\title{
Degradation of trimethoprim by sulfate radical-based advanced oxidation processes: kinetics, mechanisms, and effects of natural water matrices
}

\author{
Yiting Luo ${ }^{1,2} \cdot$ Rongkui Su ${ }^{2}$ (D) Haisong $\mathrm{Yao}^{2} \cdot$ Aoshan $\mathrm{Zhang}^{2} \cdot$ Siyuan Xiang ${ }^{2} \cdot$ Lei Huang $^{3}$ \\ Received: 19 October 2020 / Accepted: 22 June 2021 / Published online: 1 July 2021 \\ (C) The Author(s), under exclusive licence to Springer-Verlag GmbH Germany, part of Springer Nature 2021
}

\begin{abstract}
In this study, we investigated the removal efficiency of a broad-spectrum antimicrobial agent trimethoprim (TMP) in a UVactivated persulfate system (UV/PS). The pseudo-first-order reaction kinetic model based on the steady-state hypothesis was used to explain TMP degradation behavior in UV-activated persulfate system. Due to the low quantum yield and molar absorptivity of TMP at $254 \mathrm{~nm}$, the direct photolysis of TMP was slower. Since the free radicals generated by adding $\mathrm{H}_{2} \mathrm{O}_{2}$ or PS to the system can react with TMP, the degradation rate was significantly accelerated, and $\mathrm{SO}_{4}^{--}$played a dominant role in the UV/PS system. $k_{\mathrm{HO}}{ }^{\text {, TMP }}$ and $k_{\mathrm{SO}_{4}^{-}, \mathrm{TMP}}$ were determined by the pseudo-first-order reaction kinetic model to be $6.02 \times 10^{9}$ and $3.88 \times 10^{9} \mathrm{M}^{-1} \mathrm{~s}^{-1}$, respectively. The values were consistent with competitive kinetic measurements. The pseudo-first-order reaction kinetics model can predict and explain the effect of PS concentration, natural organic matter, and chloride ion on the TMP degradation in the UV/ PS system. The observed pseudo first-order rate constants for TMP degradation $\left(k_{\text {obs }}\right)$ increased with the persulfate concentration, but it significantly decreased in the presence of NOM and chloride. $\mathrm{SO}_{4}^{2-}$ has no effect on the degradation of TMP, while $\mathrm{HCO}_{3}^{-}$ promotes the degradation and $\mathrm{NO}_{3}^{-}$inhibits the degradation. The common transition metal ion (such as $\mathrm{Cu}^{2+}, \mathrm{Zn}^{2+}$, and $\mathrm{Co}^{2+}$ ) in industrial wastewater has a synergistic effect on the TMP degradation in the UV/PS system, but excessive metal ions will lead to a decrease of the degradation rate.
\end{abstract}

Keywords Sulfate radical $\cdot$ Trimethoprim $\cdot \mathrm{UV} /$ persulfate $\cdot$ Kinetics model

\section{Introduction}

Trimethoprim (TMP), a broad-spectrum antibacterial, has been widely used for its high effective and unique antibacterial

Both Yiting Luo and Rongkui Su contributed equally to this study.

Responsible Editor: Ricardo Torres-Palma

Rongkui Su

surongkui@csuft.edu.cn

Lei Huang

znhuanglei@foxmail.com

1 Key Laboratory of Jiangxi Province for Persistent Pollutants Control and Resources Recycle, Nanchang Hangkong University,

Nanchang 330063, PR China

2 School of Environmental Science and Engineering, Central South University of Forestry and Technology, Changsha 410004, PR China

3 School of Environmental Science and Engineering, Guangzhou University, Guangzhou 510006, PR China properties. TMP can enter the environmental water through the pharmaceutical wastewater generated during industrial production processes and the domestic sewage formed during daily use. TMP concentrations up to $605 \mu \mathrm{g} / \mathrm{L}$ has been detected in the Pearl River basin of China (Bu et al. 2013). Residues and accumulation of TMP in the surface water and groundwater can have a major impact on the ecological environment. The priority control of 39 commonly used medicines and personal care products was studied by considering three factors: consumption, removal efficiency, and potential ecological risk, and it was found that TMP priority control ranks among the top in China (Sui et al. 2012). However, the study of Adams et al. (2002) showed that conventional water treatment processes (aluminum salt or iron salt coagulation process) cannot effectively remove TMP in surface water and deionized water. Zhao et al. (2019) used the activated sludge (AS) process to treat high-concentration antibiotic wastewater and found that the adsorption of trimethoprim was negligible, and no biodegradation occurred during the AS process. 
Advanced oxidation technology (AOPs) with ${ }^{\circ} \mathrm{OH}$ and $\mathrm{SO}_{4}^{\circ-}$ as the main active substance is a promising treatment technology that improves the biodegradability of wastewater through oxidation or directly degrades organic pollutants through mineralization (Hou et al. 2018; Huang et al. 2020; Ji et al. 2018). 'OH is a strong oxidant, which has a high redox potential $\left(E_{0}=\right.$ 1.89 2.72 V vs. NHE). ${ }^{\circ} \mathrm{OH}$ is effective in the degradation of organic pollutants. However, $\bullet \mathrm{OH}$ has a poor selectivity, short half-life, and is easily affected by water constituents (natural organic matter, inorganic salt ions, etc.) (Wan et al. 2019). In contrast, $\mathrm{SO}_{4}^{--}$is characterized by a high redox potential $\left(E_{0}=\right.$ 2.5 3.1 V vs. NHE), strong selectivity, long half-life (30 40 $\mu \mathrm{s})$, high quantum yield, and is not easily affected by $\mathrm{pH}$ and organic matter (Avetta et al. 2015; Lutze et al. 2015). $\mathrm{SO}_{4}^{--}$has a good removal effect on emerging organic compounds (EOCs) (such as pharmaceuticals, disinfectants, and personal care products) in wastewater (Tang et al. 2019).

Persulfate has the characteristics of good stability and strong water solubility. Usually, under the conditions of transition metal ions (e.g., $\mathrm{Co}^{2+}$ and $\mathrm{Fe}^{2+}$ ), light, heat, ultrasound, PS, or PMS can be activated to produce $\mathrm{SO}_{4}^{--}$(Ji et al. 2016; Naim and Ghauch 2016; Wei et al. 2017). UV-254nm irradiation, which has been widely used for sterilization and disinfection, is also a promising method that activates PS/PMS to generate sulfate radical efficiently (Lin et al. 2020; Zhang et al. 2021). Lin et al. (2020) studied the degradation of organosilicon wastewater by UV-based advanced oxidation processes: $\mathrm{UV} / \mathrm{H}_{2} \mathrm{O}_{2}, \mathrm{UV} /$ peroxydisulfate (PDS), and $\mathrm{UV} /$ peroxymonosulfate (PMS), and the results showed that UV/ PDS achieved a higher COD removal (90.6\%) than UV/PMS $(80.8 \%)$ after a 240 min reaction time. Ran and Li (2020) studied refractory organic compounds from dinitrodiazophenol (DDNP) containing industrial wastewater degraded through two ultraviolet (UV)-based advanced oxidation processes: UV/hydrogen peroxide $\left(\mathrm{UV} / \mathrm{H}_{2} \mathrm{O}_{2}\right)$ and $\mathrm{UV} /$ potassium persulfate (UV/PS) processes, and the results showed that the UV/PS process exhibited a higher organic compound removal efficiency and better applicability. Bougdour et al. (2020) studied the removal efficiency of colors from wastewater containing mixed primary direct dyes and real textile industry wastewater using PDS (peroxydisulfate)/Fe(II)/UV process, and it was found that $\mathrm{PDS} / \mathrm{Fe}(\mathrm{II}) / \mathrm{UV}$ is the best treatment method for real textile wastewater. Zhang et al. (2015) studied the degradation of drugs and metabolites in synthetic human urine by UV, UV/ $\mathrm{H}_{2} \mathrm{O}_{2}$, and UV/PMS ( $\mathrm{pH}=6$ and $\mathrm{pH}=9$ ), respectively. The results showed that $\mathrm{UV} / \mathrm{H}_{2} \mathrm{O}_{2}$ and UV/PMS had a better degradation effect on TMP. However, the degradation of TMP by UV/PS system under neutral condition has not been reported yet. The effects of complex environmental matrices and transition metal ions present in industrial wastewater on the degradation of TMP by UV/PS are unclear.
This study aims to establish an efficient UV/PS technology to degrade EOCs in wastewater. TMP is used as the target compound. Under the steady-state assumption, the pseudofirst-order reaction kinetic model is used to study the degradation mechanism of TMP in a UV/PS system. Competitive kinetics technique and kinetics model were used to determine $k_{\mathrm{TMP}, \mathrm{SO}_{4}^{-}}$. The effects of persulfate concentration and matrix components (natural organic matters, inorganic anions) were evaluated by the kinetics model and experiment. Then, the effects of transition metal ions $\left(\mathrm{Cu}^{2+}, \mathrm{Zn}^{2+}, \mathrm{Co}^{2+}\right)$ in industrial wastewater on the photodegradation kinetics of TMP were further evaluated.

\section{Experimental method}

\section{Materials}

TMP (99.0\%), 4-chlorobenzoic acid ( $p$ CBA, 99.0\%), sodium dihydrogen phosphate (99.0\%), disodium phosphate $(99.0 \%)$, sodium persulfate $(99.0 \%)$, fulvic acid (technical), and $t$-butanol $(99.7 \%)$ were obtained from Sigma Aldrich. Copper sulfate (guaranteed reagent, GR), cobalt sulfate (GR), zinc sulfate (GR), sodium chloride (GR), sodium sulfate (analytical grade), sulfuric acid (GR), and hydrogen peroxide (30\% by weight) were obtained from Sinopharm Chemical Reagent. Deionized (DI) water was obtained from a Molresearc 1010A molecular water system.

\section{Irradiation experiments}

In the kinetics tests, the initial concentrations of the target compound TMP and probe compound $p$ CBA are both set at 10 uM. Phosphate buffer system $\left(\mathrm{NaH}_{2} \mathrm{PO}_{4} / \mathrm{Na}_{2} \mathrm{HPO}_{4}\right.$, $10 \mathrm{mM}$ ) was used to stabilize solution $\mathrm{pH}$ at 7.55 . The value of $\mathrm{pH}$ did not change during the experiments. The detailed experimental design, operation process, data collection, and result analysis had been described in our previous articles $(\mathrm{Su}$ et al. 2018; Yang et al. 2017).

\section{Analytical methods}

According to the measurement method we previously reported, the average light intensity per volume $\left(I_{0}\right)$ and effective optical path length $(b)$ were determined to be $7.496 \times 10^{-6}$ Einstein $\mathrm{L}^{-1} \mathrm{~s}^{-1}$ and $0.935 \mathrm{~cm}$, respectively (Beltran et al. 1995; Parker 1953; Yang et al. 2017).

A USB 2000+, Ocean Optics fiber optic spectrometer was used to measure the emission spectrum and light intensity of low-pressure mercury lamp. Shimadzu UV-1800 spectrometer was used to determine the absorption spectra of TMP and 
$p$ CBA (Fig. 1). A Mettler Toledo S220 pH meter was used to measure the solution $\mathrm{pH}$.

The concentration of TMP and $p$ CBA was performed using an ultra-performance liquid chromatography (Waters ACQUITY H-Class) with a BEH C18 column $(1.7 \mu \mathrm{m}$, $2.1 \mathrm{~mm} \times 50 \mathrm{~mm}$, Waters). The detailed method is shown in Table 1 .

\section{Results and discussion}

\section{Degradation of TMP in UV, UV/ $\mathrm{H}_{2} \mathrm{O}_{2}$, and UV/PS systems}

Linear regression analysis of the TMP degradation process showed that it followed the pseudo-first-order reaction kinetics. As shown in Fig. 2, under the reaction conditions of UV intensity $7.496 \times 10^{-6}$ Einstein $\mathrm{L}-1 \mathrm{~s}-1, \mathrm{pH}=7.55$, and $[\mathrm{TMP}]_{0}=10 \mu \mathrm{M}$, the initial direct photolytic degradation rate of TMP in only the UV system was $0.038 \mu \mathrm{M}$ min -1 . Without UV irradiation, the dark reaction experiments showed that TMP had no degradation. The same results were observed in the presence of $\mathrm{H}_{2} \mathrm{O}_{2}$ or PS. Therefore, the degradation of TMP under UV radiation was mainly attributed to the direct photolysis of TMP. As shown in Fig. 1, at the wavelength ranging from 250 to $260 \mathrm{~nm}$, TMP has a relative trough in the absorption of light. Therefore, the direct photolysis of TMP under $254 \mathrm{~nm}$ ultraviolet mercury lamp irradiation is slower.

The molar absorption coefficient $(\varepsilon)$ and quantum yield $(\varphi)$ are two important factors that affect the kinetics of target compound direct photolysis (Pereira et al. 2007). The molar absorption coefficient is a measure of the absorb light ability of a target compound at a specific wavelength $(\lambda)$. $\varepsilon$ can be calculated as Eq. 1.

$A=\varepsilon_{\mathrm{TMP}} \times[\mathrm{TMP}] \times l$

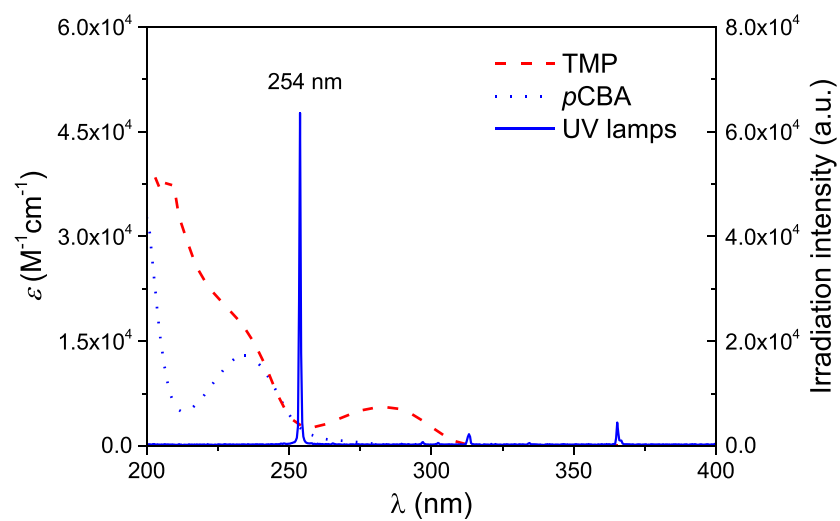

Fig. 1 Decadic molar absorption coefficient $(\varepsilon)$ of TMP and $p$ CBA $(\mathrm{pH}=$ 7.55) with reference to the UV lamp emission spectra from 200 to $400 \mathrm{~nm}$
$A$ is the absorbance of $10 \mu \mathrm{M}$ TMP solutions. The TMP solution $\mathrm{pH}$ is adjusted to 7.55 by phosphate buffer solution. $l$ is the path length of quartz cuvette. In this study, a $1 \mathrm{~cm}$ path length quartz cuvette was used to measure the TMP solution absorbance. Figure 1 illustrates the decadic molar extinction coefficient for TMP with reference to Hg lamp emission spectra. At the wavelength of $254 \mathrm{~nm}$, the $\varepsilon$ values of TMP were $3078.56 \mathrm{M}^{-1} \mathrm{~cm}^{-1}$, which is consistent with the reported value of $2942 \mathrm{M}^{-1} \mathrm{~cm}^{-1}$ (Baeza and Knappe 2011). $\varepsilon_{\text {TMP }}$ was lower than the reported value of carbamazepine $\left(6070 \mathrm{M}^{-1} \mathrm{~cm}^{-1}\right)$ and sulfamethoxazole $\left(16580 \mathrm{M}^{-1} \mathrm{~cm}^{-1}\right)$, while it was higher than that of ibuprofen $\left(256 \mathrm{M}^{-1} \mathrm{~cm}^{-1}\right)$ and bisphenol $(750$ $\mathrm{M}^{-1} \mathrm{~cm}^{-1}$ ) (Baeza and Knappe 2011; Pereira et al. 2007; Yuan et al. 2009).

The quantum yield described the ratio of the total numbers of molecules of the compound destroyed to the total numbers of photons absorbed by the system. The quantum yield of TMP can be calculated as follows (Pereira et al. 2007):

$\varphi_{\mathrm{TMP}}=\frac{r_{\mathrm{UV}}}{I_{0} \times\left(1-10^{-\varepsilon_{\mathrm{TMP}} b[\mathrm{TMP}]}\right)}$

where $\varphi_{\text {TMP }}$ is the quantum yield of TMP at $254 \mathrm{~nm}$ (mol Einstein $\left.^{-1}\right), r_{\mathrm{uv}}\left(\mathrm{M} \mathrm{s}^{-1}\right)$ is the direct photolytic degradation rate at an initial concentration of $10 \mu \mathrm{M} . I_{0}$ is the incident UV intensity, $\varepsilon_{\mathrm{TMP}}$ is the molar extinction coefficient of TMP at wavelength $254 \mathrm{~nm}$, and $b$ is the reactor light path. $\varphi_{\text {TMP }}$ was calculated to be $1.29 \times 10^{-3} \mathrm{~mol} \mathrm{Einstein}^{-1}$, which was close to the reported value of $1.18 \times 10^{-3} \mathrm{M}^{-1} \mathrm{~cm}^{-1}$ (Baeza and Knappe 2011). Different Pharmaceutical and Personal Care Products (PPCPs) have different molecular structures, which can result in different quantum yield values (Yuan et al. 2009). The value of $\varphi_{\text {TMP }}$ was relatively low compared to the values of other PPCPs (ibuprofen, $0.192 \mathrm{M}^{-1} \mathrm{~cm}^{-1}$ and sulfamethoxazole, $0.0215 \mathrm{M}^{-1} \mathrm{~cm}^{-1}$ ) (Yang et al. 2016; Yuan et al. 2009).

Due to the relatively low molar absorptivity and extremely low quantum yield, the direct photolysis degradation rate of TMP was slow. As shown in Fig. 2, the degradation kinetics of TMP was significantly enhanced by adding $100 \mu \mathrm{M} \mathrm{H}_{2} \mathrm{O}_{2}$ / PS compared to direct photolysis. The initial degradation rate in the $\mathrm{UV} / \mathrm{H}_{2} \mathrm{O}_{2}$ and $\mathrm{UV} / \mathrm{PS}$ systems was $1.657 \mu \mathrm{M} \mathrm{min}^{-1}$ and $2.581 \mu \mathrm{M} \mathrm{min}^{-1}$, respectively. These results indicated that the degradation of TMP in the UV/ $\mathrm{H}_{2} \mathrm{O}_{2}$ or UV/PS systems included direct photolysis and radical degradation, but radical degradation played a major role (more than 95\%). The enhanced degradation of TMP with the addition of $\mathrm{H}_{2} \mathrm{O}_{2}$ or PS was due to the fact that TMP degradation mainly contributed to ${ }^{\circ} \mathrm{OH} / \mathrm{SO}_{4}^{--}$radical-mediated oxidation. The results were consistent with the results reported by Kwon et al. (2015), and they also demonstrated that ${ }^{\circ} \mathrm{OH} / \mathrm{SO}_{4}^{-}$played a major role in the degradation of ibuprofen by $\mathrm{UV} / \mathrm{H}_{2} \mathrm{O}_{2}$ or UV/PS. 
Table 1 The detailed method of measure the concentration of TMP and $p$ CBA

\begin{tabular}{|c|c|c|c|c|c|c|}
\hline Compound & Acetonitrile & $\begin{array}{l}\text { Phosphate buffer } \\
(20 \mathrm{mM} \text { and } \mathrm{pH} 3)\end{array}$ & $\begin{array}{l}\lambda \\
\mathrm{nm}\end{array}$ & $\begin{array}{l}\text { Flow rate } \\
\mathrm{mL} \\
\min ^{-1}\end{array}$ & $\begin{array}{l}\text { Injection } \\
\text { volume } \\
\mu l\end{array}$ & $\begin{array}{l}\text { Column } \\
\text { temperature } \\
{ }^{\circ} \mathrm{C}\end{array}$ \\
\hline $\begin{array}{l}\text { TMP } \\
p \text { CBA }\end{array}$ & $\begin{array}{l}15 \% \\
30 \%\end{array}$ & $\begin{array}{l}85 \% \\
70 \%\end{array}$ & $\begin{array}{l}285 \\
238\end{array}$ & 0.3 & 5 & 35 \\
\hline
\end{tabular}

Therefore, the degradation rate constants of TMP largely depended on the formation of ${ }^{\circ} \mathrm{OH} / \mathrm{SO}_{4}^{--}$in the UV system.

The competitive kinetics method was used to determine the second-order rate constants of TMP with $\mathrm{SO}_{4}^{--}\left(k_{\mathrm{SO}_{4}^{-}, \mathrm{TMP}}\right)$, and $p \mathrm{CBA}\left(k_{\mathrm{SO}_{4}^{-}, p \mathrm{CBA}}=3.60 \times 10^{8} \mathrm{M}^{-1} \mathrm{~s}^{-1}\right)$ was chosen as a reference compound in this study (Kwon et al. 2015). The $1 \mathrm{mM} t$-butanol was added to suppress any contribution of 'OH in oxidizing TMP. The competitive kinetics method had been described in detail in our previous study (Yang et al. 2017). Figure 3 shows that an average reaction rate constant ratio between TMP and $p \mathrm{CBA}$ with $\mathrm{SO}_{4}^{--}$was 10.58. The $k_{\mathrm{SO}_{4}^{-}}$,TMP values were determined to be $3.81 \times 10^{9}$ $\mathrm{M}^{-1} \mathrm{~s}^{-1}$. It was lower than the reported value of $7.71 \times 10^{9} \mathrm{M}^{-1}$ $\mathrm{s}^{-1}$ (Zhang et al. 2015). $\mathrm{pH}$ values determine the morphology of TMP in the system. The possible reason was that our $\mathrm{pH}$ conditions $(\mathrm{pH}=7.55)$ are different from those of Zhang $(\mathrm{pH}$ $=6)$.

\section{Pseudo first-order reaction kinetics}

The steady-state approximation for the kinetic description of radicals was also used to estimate the $k_{\mathrm{SO}_{4}^{-} \text {,IBU }}$ (Luo et al. 2016a; Yang et al. 2017). The model was developed based on the hypothesis that the degradation of the target compound depended primarily on radicals (i.e., $\mathrm{SO}_{4}^{--}$and ${ }^{\circ} \mathrm{OH}$ ) generated

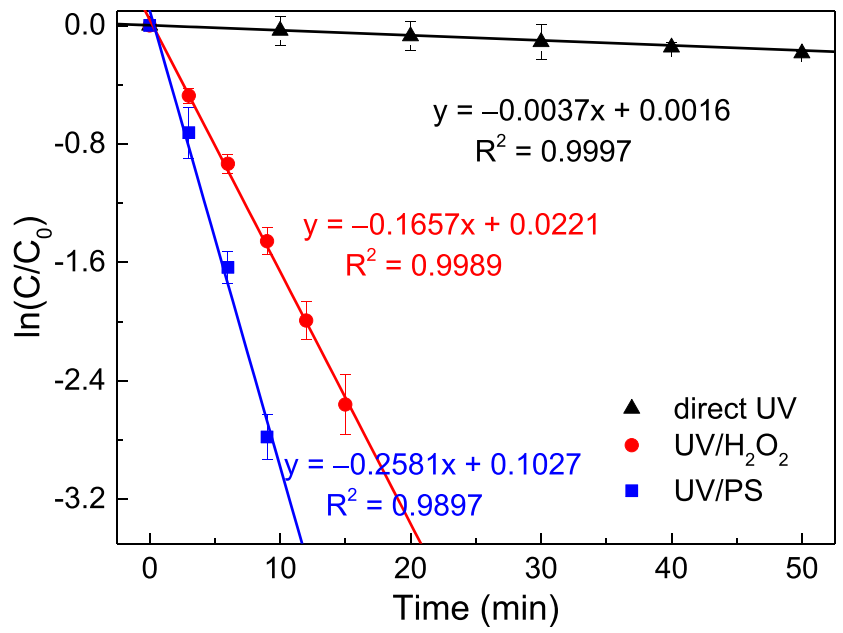

Fig. 2 Time-dependent degradation kinetics of TMP in the UV, UV/ $\mathrm{H}_{2} \mathrm{O}_{2}$, and UV/PS systems $\left([\mathrm{TMP}]_{0}=10 \mu \mathrm{M},\left[\mathrm{H}_{2} \mathrm{O}_{2}\right]=[\mathrm{PS}]=100\right.$ $\mu \mathrm{M}, \mathrm{pH}=7.55$, and $I_{0}=7.496 \times 10^{-6}$ Einstein $\left.\mathrm{L}^{-1} \mathrm{~s}^{-1}\right)$. The degradation was fit to a pseudo first-order kinetic model (lines) from the irradiation of PS. $\mathrm{SO}_{4}^{\circ-}$ was produced from activation of $\mathrm{S}_{2} \mathrm{O}_{8}^{2-}$ by $\mathrm{UV}$ and ${ }^{\circ} \mathrm{OH}$ was simultaneously formed from the reaction of $\mathrm{SO}_{4}^{--}$with $\mathrm{H}_{2} \mathrm{O}$ or $\mathrm{OH}^{-}$. The reactions in the UV/PS system and these second-order rate constants are presented in Table 2.

Under steady-state conditions, $k_{\mathrm{SO}_{4}^{-}, \mathrm{TMP}},\left[\mathrm{SO}_{4}^{-}\right]_{\mathrm{SS}}$ and $\left[\mathrm{HO}^{\circ}\right]_{\mathrm{SS}}$ can be expressed (for detailed derivation process, see previous paper, Yang et al. 2017):

$k_{\mathrm{SO}_{4}^{-}, \mathrm{TMP}}=\frac{r_{0, \mathrm{SO}_{4}^{-}} k_{\mathrm{HO}}, \mathrm{TMP} \alpha-\beta\left(k_{\mathrm{app}}-k_{\mathrm{UV}}\right)}{\left(k_{\mathrm{app}}-k_{\mathrm{UV}}\right)[\mathrm{TMP}]-r_{0, \mathrm{SO}_{4}^{-}}}$
$\left[\mathrm{SO}_{4}^{-}\right]_{\mathrm{SS}}=\frac{\left(k_{\mathrm{app}}-k_{\mathrm{UV}}\right)[\mathrm{TMP}]-r_{0, \mathrm{SO}_{4}^{-}}}{\alpha k_{\mathrm{HO}, \mathrm{TMP}}[\mathrm{TMP}]-\beta}$
$\left[\mathrm{HO}^{\bullet}\right]_{\mathrm{SS}}=\frac{\alpha\left(\left(k_{\mathrm{app}}-k_{\mathrm{UV}}\right)[\mathrm{TMP}]-r_{0, \mathrm{SO}_{4}^{-}}\right)}{\alpha k_{\mathrm{HO}} ; \mathrm{TMP}[\mathrm{TMP}]-\beta}$
$\alpha=\frac{k_{2}\left[\mathrm{OH}^{-}\right]+k_{3}\left[\mathrm{H}_{2} \mathrm{O}\right]}{k_{\mathrm{HO}}, \mathrm{TMP}}[\mathrm{TMP}]+k_{7}\left[\mathrm{~S}_{2} \mathrm{O}_{8}^{2-}\right]+k_{11}\left[\mathrm{H}_{2} \mathrm{PO}_{4}^{-}\right]+k_{12}\left[\mathrm{HPO}_{4}^{2-}\right]$

$\beta=k_{2}\left[\mathrm{OH}^{-}\right]+k_{3}\left[\mathrm{H}_{2} \mathrm{O}\right]+k_{4}\left[\mathrm{~S}_{2} \mathrm{O}_{8}^{2-}\right]+k_{9}\left[\mathrm{H}_{2} \mathrm{PO}_{4}^{-}\right]+k_{10}\left[\mathrm{HPO}_{4}^{2-}\right]$

The average of $r_{0 \_\mathrm{SO}_{4}^{-}}$and $k_{\text {app }}$ was $4.623 \times 10^{-8} \mathrm{M} \mathrm{s}^{-1}$ and $4.301 \times 10^{-3} \mathrm{~s}^{-1}$, respectively. The value of $\alpha$ was $8.78 \times 10^{-3}$ (unitless), and $\beta$ was $9.00 \times 10^{3} \mathrm{~s}^{-1}$ as calculated. $k_{\mathrm{HO}}$,TMP was

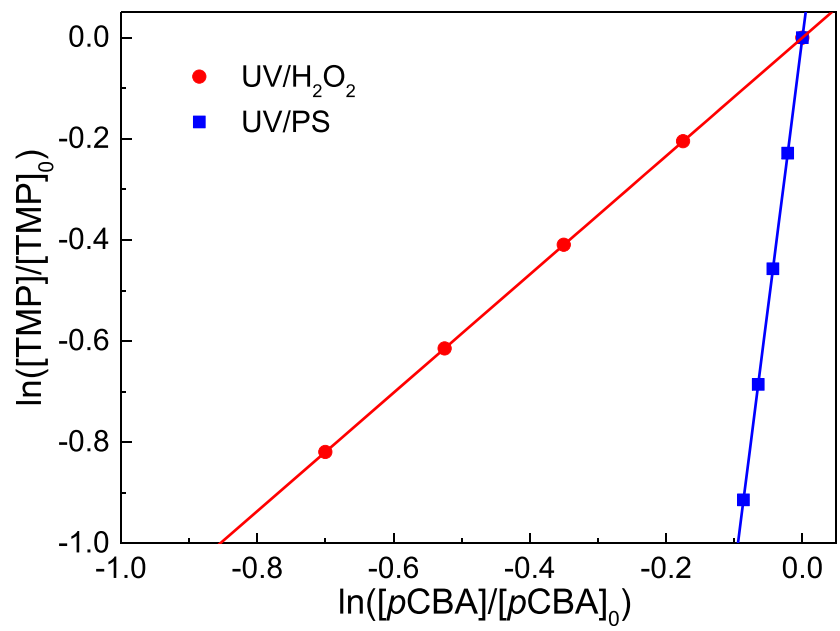

Fig. 3 Competitive oxidation of TMP and $p$ CBA in $\mathrm{UV} / \mathrm{H}_{2} \mathrm{O}_{2}$ and $\mathrm{UV} /$ PS system 
Table 2 Summary of the reactions in the UV/PS system ( $\mathrm{pH}=7.55$ and $10 \mathrm{mM}$ phosphate buffer $)$

\begin{tabular}{|c|c|c|c|}
\hline \# & Reaction & $k\left(\mathrm{M}^{-1} \mathrm{~s}^{-1}\right.$, unless specified $)$ & Reference or note \\
\hline 1 & $\mathrm{~S}_{2} \mathrm{O}_{8}^{2-}+h v \rightarrow 2 \mathrm{SO}_{4}^{--}$ & $r_{0, \mathrm{SO}_{4}^{-}}=2 \varphi_{\mathrm{S}} E_{\mathrm{S}}, \mathrm{M} \mathrm{s}^{-1}$ & Measured in this study \\
\hline 2 & $\mathrm{SO}_{4}^{--}+\mathrm{OH}^{-} \rightarrow \mathrm{SO}_{4}^{2-}+{ }^{\cdot} \mathrm{OH}$ & $k_{2}=6.5 \times 10^{7}$ & (Neta et al. 1977) \\
\hline 3 & $\mathrm{SO}_{4}^{--}+\mathrm{H}_{2} \mathrm{O} \rightarrow \mathrm{HSO}_{4}^{-}+{ }^{\cdot} \mathrm{OH}$ & $k_{3}=8.3$ & (Yu et al. 2004) \\
\hline 4 & $\mathrm{SO}_{4}^{--}+\mathrm{S}_{2} \mathrm{O}_{8}^{2-} \rightarrow \mathrm{S}_{2} \mathrm{O}_{8}^{--}+\mathrm{SO}_{4}^{2-}$ & $k_{4}=5.5 \times 10^{5}$ & (Yu et al. 2004) \\
\hline 5 & $\mathrm{SO}_{4}^{--}+\mathrm{SO}_{4}^{--} \rightarrow \mathrm{S}_{2} \mathrm{O}_{8}^{2-}$ & $k_{5}=4.4 \times 10^{8}$ & (Klaning et al. 1991) \\
\hline 6 & $\mathrm{SO}_{4}^{--}+{ }^{\cdot} \mathrm{OH} \rightarrow \mathrm{H}^{+}+\mathrm{SO}_{4}^{2-}+\mathrm{O}_{2}$ & $k_{6}=9.5 \times 10^{9}$ & (Klaning et al. 1991) \\
\hline 7 & $\cdot \mathrm{OH}+\mathrm{S}_{2} \mathrm{O}_{8}^{2-} \rightarrow \mathrm{S}_{2} \mathrm{O}_{8}^{--}+\mathrm{OH}^{-}$ & $k_{7}=1.4 \times 10^{7}$ & (Buxton et al. 1988) \\
\hline 8 & $\cdot \mathrm{OH}+{ }^{\cdot} \mathrm{OH} \rightarrow \mathrm{H}_{2} \mathrm{O}_{2}$ & $k_{8}=5.5 \times 10^{9}$ & (Buxton et al. 1988) \\
\hline 9 & $\mathrm{H}_{3} \mathrm{PO}_{4} \rightleftharpoons \mathrm{H}^{+}+\mathrm{H}_{2} \mathrm{PO}_{4}^{-}$ & $\mathrm{p} K_{\mathrm{a} 1}=2.1$ unitless & (Stumm and Morgan 1996) \\
\hline 10 & $\mathrm{H}_{2} \mathrm{PO}_{4}^{-} \rightleftharpoons \mathrm{H}^{+}+\mathrm{HPO}_{4}^{2-}$ & $\mathrm{p} K_{\mathrm{a} 2}=7.2$ unitless & (Stumm and Morgan 1996) \\
\hline 11 & $\mathrm{HPO}_{4}^{2-} \rightleftharpoons \mathrm{H}^{+}+\mathrm{PO}_{4}^{3-}$ & $\mathrm{p} K_{\mathrm{a} 3}=12.3$ unitless & (Stumm and Morgan 1996) \\
\hline 12 & $\mathrm{SO}_{4}^{--}+\mathrm{H} 2 \mathrm{PO}_{4}^{-} \rightarrow$ products & $k_{9}<7.2 \times 10^{4}$ & (Neta et al. 1977) \\
\hline 13 & $\mathrm{SO}_{4}^{--}+\mathrm{H} 2 \mathrm{PO}_{4}^{2-} \rightarrow$ products & $k_{10}=1.2 \times 10^{6}$ & (Neta et al. 1977) \\
\hline 14 & $\cdot \mathrm{OH}+\mathrm{H}_{2} \mathrm{PO}_{4}^{-} \rightarrow \mathrm{HPO}_{4}^{-}+\mathrm{H} 2 \mathrm{O}$ & $k_{11}=2.0 \times 10^{4}$ & (Buxton et al. 1988) \\
\hline \multirow[t]{2}{*}{15} & $\cdot \mathrm{OH}+\mathrm{HPO}_{4}^{2-} \rightarrow \mathrm{HPO}_{4}^{--}+\mathrm{OH}^{-}$ & $k_{12}=1.5 \times 10^{5}$ & (Buxton et al. 1988) \\
\hline & In the presence of $p \mathrm{CBA}$ and $t$-butanol & & \\
\hline 16 & $\mathrm{SO}_{4}^{--}+t$-butanol $\rightarrow$ products & $k_{13}=4.0 \times 10^{5}$ & (Neta et al. 1977) \\
\hline 17 & $\cdot \mathrm{OH}+t$-butanol $\rightarrow$ products & $k_{14}=6.0 \times 10^{8}$ & (Buxton et al. 1988) \\
\hline 18 & $\mathrm{SO}_{4}^{--}+p \mathrm{CBA} \rightarrow$ products & $k_{15}=3.6 \times 10^{8}$ & (Fang and Shang 2012) \\
\hline \multirow[t]{2}{*}{19} & $\cdot \mathrm{OH}+p \mathrm{CBA} \rightarrow$ products & $k_{16}=5.0 \times 10^{9}$ & (Fang and Shang 2012) \\
\hline & In the presence of $\mathrm{HA}$ & & \\
\hline 20 & $\mathrm{SO}_{4}^{--}+\mathrm{FA} \rightarrow$ products & $k_{17}=9.3 \times 10^{3} \mathrm{~L} \mathrm{mgC}^{-1} \mathrm{~s}^{-1}$ & measured in this study \\
\hline \multirow[t]{2}{*}{21} & $\cdot \mathrm{OH}+\mathrm{FA} \rightarrow$ products & $k_{18}=1.4 \times 10^{4} \mathrm{~L} \mathrm{mgC}^{-1} \mathrm{~s}^{-1}$ & (Lutze et al. 2015) \\
\hline & In the presence of $\mathrm{CI}^{-}$ & & \\
\hline 22 & $\mathrm{SO}_{4}^{--}+\mathrm{Cl}^{-} \rightarrow \mathrm{Cl}^{-}+\mathrm{SO}_{4}^{2-}$ & $k_{19}=3.0 \times 10^{8}$ & (Das 2001) \\
\hline 23 & $\cdot \mathrm{OH}+\mathrm{Cl}^{-} \rightarrow \mathrm{ClOH}^{\bullet}$ & $k_{20}=4.3 \times 10^{9}$ & (Jayson et al. 1973) \\
\hline 24 & $\mathrm{Cl}^{\bullet}+\mathrm{OH}^{-} \rightarrow \mathrm{ClOH}^{\bullet}$ & $k_{21}=1.8 \times 10^{10}$ & (Kläning and Wolff 1985) \\
\hline 25 & $\mathrm{Cl}^{\bullet}+\mathrm{H}_{2} \mathrm{O} \rightarrow \mathrm{ClOH}^{\cdot}+\mathrm{H}^{+}$ & $k_{22}=2.5 \times 10^{5}$ & (Jayson et al. 1973) \\
\hline 26 & $\mathrm{ClOH}^{\cdot} \rightarrow \mathrm{Cl}^{-}+{ }^{\cdot} \mathrm{OH}$ & $k_{23}=6.0 \times 10^{9}$ & (Jayson et al. 1973) \\
\hline 27 & $\mathrm{ClOH}^{\bullet}+\mathrm{H}^{+} \rightarrow \mathrm{Cl}^{-}+\mathrm{H}_{2} \mathrm{O}$ & $k_{24}=2.1 \times 10^{10}$ & (Kläning and Wolff 1985) \\
\hline 28 & $\mathrm{Cl}^{\cdot}+\mathrm{Cl}^{-} \rightarrow \mathrm{Cl}_{2}^{-}$ & $k_{25}=8.5 \times 10^{9}$ & (Yu et al. 2004) \\
\hline 29 & $\mathrm{Cl}_{2}^{-}+\mathrm{H}_{2} \mathrm{O} \rightarrow \mathrm{HClOH}+\mathrm{Cl}^{-}$ & $k_{26}=1.3 \times 10^{3}$ & (McElroy 1990) \\
\hline 30 & $\mathrm{Cl}_{2}^{-}+\mathrm{OH}^{-} \rightarrow \mathrm{ClOH}^{--}+\mathrm{Cl}^{-}$ & $k_{27}=4.5 \times 10^{7}$ & (Kläning and Wolff 1985) \\
\hline 31 & $\mathrm{Cl}_{2}^{--}+\mathrm{Cl}_{2}^{-} \rightarrow \mathrm{Cl}_{2}+2 \mathrm{Cl}^{-}$ & $k_{28}=9.0 \times 10^{8}$ & (Yu et al. 2004) \\
\hline \multirow[t]{2}{*}{32} & $\mathrm{Cl}_{2}^{--}+\mathrm{Cl}^{\cdot} \rightarrow \mathrm{Cl}_{2}+\mathrm{Cl}^{-}$ & $k_{29}=2.1 \times 109$ & (Nikravesh et al. 2020) \\
\hline & Degradation of TMP & & \\
\hline 33 & $\mathrm{TMP}+h v \rightarrow$ products & $r_{u v}, \mathrm{M} \mathrm{s}^{-1}$ & Measured in this study \\
\hline 34 & $\cdot \mathrm{OH}+\mathrm{TMP} \rightarrow$ products & $k_{\mathrm{TMP}, \mathrm{HO}}$ & measured in this study \\
\hline 35 & $\mathrm{SO}_{4}^{--}+\mathrm{TMP} \rightarrow$ products & $k_{\mathrm{TMP}, \mathrm{SO}_{4}^{-}}^{-}$ & measured in this study \\
\hline
\end{tabular}

Note: In phosphate buffer, $\mathrm{H}_{2} \mathrm{PO}_{4}^{-}$and $\mathrm{HPO}_{4}^{2-}$ are the predominant species at $\mathrm{pH} 7.55$

$6.02 \pm 0.13 \times 10^{9} \mathrm{M}^{-1} \mathrm{~s}^{-1}$ from competition kinetics method in

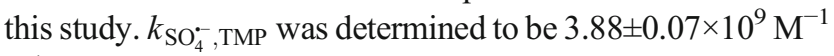
$\mathrm{s}^{-1}$, which was consistent with the value determined by competitive kinetics. The average of $\left[\mathrm{SO}_{4}^{--}\right]_{\mathrm{SS}}$ and $\left[\mathrm{HO}^{\circ}\right]_{\mathrm{SS}}$ was $9.46 \times 10^{-15} \mathrm{M}$ and $1.08 \times 10^{-12} \mathrm{M}$, respectively.
With the values of $k_{\mathrm{HO}}$, TMP $, k_{\mathrm{SO}_{4}^{-}, \mathrm{TMP}},\left[\mathrm{HO}^{\circ}\right]_{\mathrm{SS}},\left[\mathrm{SO}_{4}^{--}\right]_{\mathrm{SS}}$, the contribution of direct $\mathrm{UV}$ photolysis, ${ }^{\circ} \mathrm{OH}$, and $\mathrm{SO}_{4}^{-}$in degrading TMP was calculated. In the UV/PS system, the values of $r_{\mathrm{uv}}, r_{\mathrm{HO}}$, and $r_{\mathrm{SO}_{4}^{-}}$were determined to be $6.22 \times 10^{-10} \mathrm{M} \mathrm{s}^{-1}, 5.69 \times 10^{-10} \mathrm{M} \mathrm{s}^{-1}$, and $4.18 \times 10^{-8} \mathrm{M} \mathrm{s}^{-1}$, 
respectively. Thus, approximately $1.45 \%$ of TMP removal was attributed to direct photolysis and ${ }^{\circ} \mathrm{OH}$ only contributed to about $1.32 \%$ of the total degradation, indicating that $\mathrm{SO}_{4}^{-}$ played a dominant role during the degradation process.

The pseudo first-order reaction kinetics model can be used to study and simulate the effects of other factors on TMP degradation. In this study, we used the pseudo first-order reaction kinetics model to predict and explain the effects of PS concentration and matrix components on TMP degradation by UV/PS process. Then the contributions of ${ }^{\circ} \mathrm{OH}$ and $\mathrm{SO}_{4}^{--}$to TMP degradation (i.e., $k_{\mathrm{cal}, \mathrm{UV}}, k_{\mathrm{cal}} \cdot \mathrm{OH}_{\mathrm{OH}}$ and $k_{\mathrm{cal}, \mathrm{SO}_{4}^{-}}$) under various experimental conditions were calculated by Eqs. 8, 9, and 10 , respectively.

$$
\begin{aligned}
& k_{\mathrm{cal}, \mathrm{UV}}=\varphi_{\mathrm{TMP}} \times E_{0} \times \frac{b \varepsilon_{\mathrm{TMP}}}{A} \times\left(1-\mathrm{e}^{-2.303 A}\right) \\
& k_{\mathrm{cal}, \mathrm{HO}}=k_{\mathrm{TMP}, \mathrm{HO}} \times\left[\mathrm{HO}^{\circ}\right]_{\mathrm{SS}} \\
& k_{{\mathrm{cal}, \mathrm{SO}_{4}^{-}}^{-}}=k_{\mathrm{TMP}, \mathrm{SO}_{4}^{-}} \times\left[\mathrm{SO}_{4}^{--}\right]_{\mathrm{SS}}
\end{aligned}
$$

The total contribution of ${ }^{\circ} \mathrm{OH}$ and $\mathrm{SO}_{4}^{--}$to TMP degradation $\left(k_{\text {cal }}\right)$ can be expressed by Eq. 11 .

$k_{\mathrm{cal}}=k_{\mathrm{cal}, \mathrm{UV}}+k_{\mathrm{cal}, \mathrm{HO}}+k_{{\mathrm{cal}, \mathrm{SO}_{4}^{-}}^{-}}$

\section{Effect of the initial oxidant concentration}

The degradation rates of TMP were affected by the PS concentration in the UV/PS system. As shown in Fig. 4, the observed pseudo first-order rate constants (in the unit of $\mathrm{s}^{-1}$ ) for TMP degradation $\left(k_{\text {obs }}\right)$ increased from $4.95 \times 10^{-3} \mathrm{~s}^{-1}$ to $25.12 \times 10^{-3} \mathrm{~s}^{-1}$ when PS concentration increases from $100 \mu \mathrm{M}$ to $500 \mu \mathrm{M}$. This result could be accurately predicted by the kinetic model (the calculated result, $k_{\mathrm{cal}}$ ). The contributions of direct $\mathrm{UV},{ }^{\circ} \mathrm{OH}$, and $\mathrm{SO}_{4}^{--}$to TMP degradation were

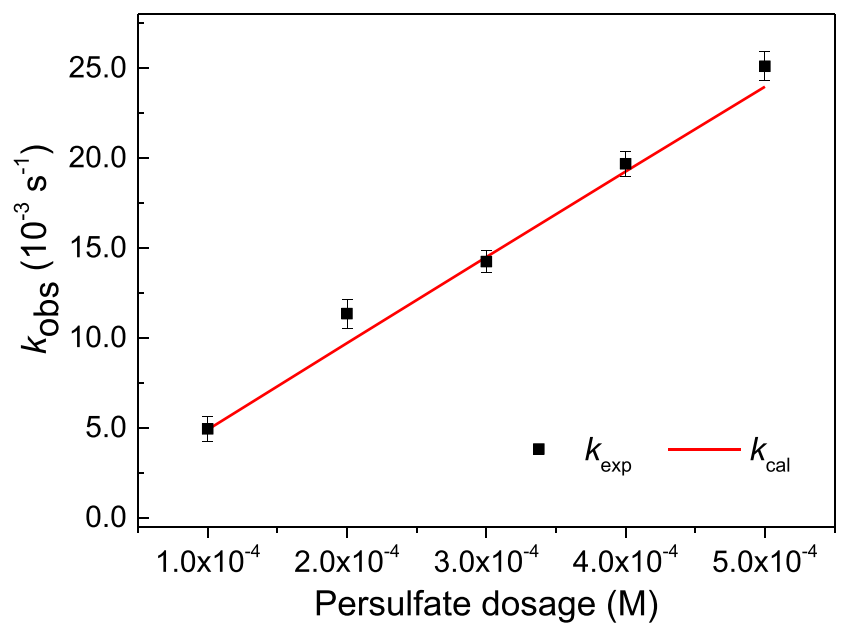

Fig. 4 Impacts of PS concentration on the pseudo first-order constants of $\operatorname{TMP}(k) .\left([\mathrm{TMP}]_{0}=10 \mu \mathrm{M}, \mathrm{pH}=7.55\right.$, and $I_{0}=7.496 \times 10^{-6}$ Einstein $\mathrm{L}^{-1}$ $\left.\mathrm{s}^{-1}\right)$ also calculated. As the dose of PS increased, the contribution rate of direct photolysis was significantly reduced due to the competition of PS for UV, and there was no significant change in the contribution rate of ${ }^{\circ} \mathrm{OH}$. However, the results showed that $\mathrm{SO}_{4}^{--}$was the main reactive species in the UV/PS system at $\mathrm{pH} 7.55$, with a contribution to TMP degradation $\left(k_{\mathrm{cal}, \mathrm{SO}_{4}^{-}}\right)$ always greater than $97 \%$. This result was also consistent with the previous study of Luo et al. (2016a) who found that the contribution of $\mathrm{SO}_{4}^{--}$was increased from 82.6 to $92.5 \%$ with the increase of PS concentration from 100 to $500 \mu \mathrm{M}$ in the degradation of 2,4,6-trichloroanisole. However, Xie et al. (2015) found that the contribution of ${ }^{\circ} \mathrm{OH}$ was about 3.5 times and 2.0 times higher than $\mathrm{SO}_{4}^{--}$for 2-methylisoborneol and geosmin degradation, respectively. This discrepancy might be ascribed to the secondary reaction rate constant of radicals with the target compound and the concentration of free radicals in the system. The $k_{\cdot \mathrm{OH}} / k_{\mathrm{SO}_{4}^{-}}$of 2,4,6-trichloroanisole and TMP were 1.37 and 1.55 , which is smaller than the value of 2 methylisoborneol and geosmin (10.24 and 7.50, respectively). On the other hand, $\left[\mathrm{SO}_{4}^{-}\right]_{\mathrm{SS}}$ was expected to be about two orders of magnitude higher than $\left[\mathrm{HO}^{*}\right]_{\mathrm{SS}}$ based on Eqs. 4 and 5, which was consistent with Luo's study (Luo et al. 2016a). For instance, the calculated steady-state concentrations of $\mathrm{S}$ $\mathrm{O}_{4}^{--}$and ${ }^{\circ} \mathrm{OH}$ were about $1.08 \times 10^{-12} \mathrm{M}$ and $9.46 \times 10^{-15} \mathrm{M}$ at $[\mathrm{PS}]=100 \mu \mathrm{M}$, respectively.

\section{Effect of NOM}

NOM is a mixture of macromolecular organic compounds prevalent in the natural environment, widely distributed in soil, lake, river, and ocean. The impact of NOM on the degradation of organic contaminants has received more and more attention. Fulvic acid (FA) is a mixture of non-homogeneous compounds that can be dissolved in a base but cannot be dissolved in acid (Fu et al. 2006). Since FA was the main component of NOM, the effect of NOM in the UV/PS processes was examined by adding different concentrations of FA $\left(0 \sim 2.88 \mathrm{mgC} \mathrm{L}^{-1}\right)$ in this study. Figure 5 shows that $k_{\text {obs }}$ decreased from $11.36 \times 10^{-3} \mathrm{~s}^{-1}$ to $7.07 \times 10^{-3} \mathrm{~s}^{-1}$ with FA concentrations increasing from 0 to $2.88 \mathrm{mgC} \mathrm{L}^{-1}$. The experimental data was basically consistent with the modeling results $\left(k_{\mathrm{cal}}\right)$. Two factors could be responsible for the inhibitory effect of FA on TMP degradation. First, FA would exert an inner filter effect for the photolysis of persulfate, and $A$ can be modified to $A=b\left(\varepsilon_{\mathrm{TMP}}[\mathrm{TMP}]+\varepsilon_{\mathrm{S}_{2} \mathrm{O}_{8}^{2-}}\left[\mathrm{S}_{2} \mathrm{O}_{8}^{2-}\right]+\varepsilon_{\mathrm{FA}}[\mathrm{FA}]\right)$ $\left(\varepsilon_{\mathrm{FA}}=0.10 \mathrm{~L} \mathrm{mgC}^{-1} \mathrm{~cm}^{-1}\right.$ measured in this work). Second, FA acted as a radical scavenger as described by Eqs. 20 and 21 in Table 2. The kinetic model was used to estimate the relative contributions of the inner filter effect and radical scavenger in decreasing $k_{\text {obs }}$ values. If the inner filter effect of FA was not accounted for $k$, then $\varepsilon_{\mathrm{FA}}$ was equal to zero. As we can see from Fig. $5, k_{\text {cal }}$ (green line) slightly changed as compared to 


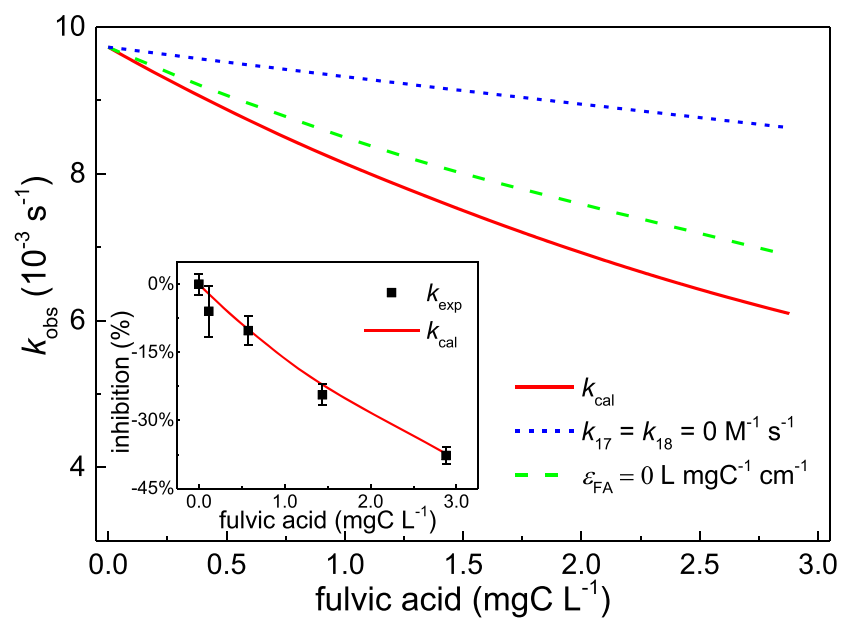

Fig. 5 Impacts of fulvic acid on the pseudo first-order constants of TMP $(k)\left([\mathrm{TMP}]_{0}=10 \mu \mathrm{M},[\mathrm{PS}]_{0}=200 \mu \mathrm{M}, \mathrm{pH}=7.55\right.$, and $E_{0}=7.496 \times 10^{-6}$ Einstein $\mathrm{L}^{-1} \mathrm{~s}^{-1}$ )

the experimental data (black dots) by assuming $\varepsilon_{\mathrm{FA}}=0$. If FA did not have a radical scavenging effect (i.e., $k_{17}$ and $k_{18}$ values in Table 2 were equal to zero), $k_{\text {cal }}$ (blue line) greatly deviated from the experimental data (black dots) in Fig. 5. These results indicated that the radical scavenger effect of FA played a more significant role than the inner filter effect in decreasing TMP degradation rates. At the same time, the model calculation results showed that as the concentration of fulvic acid increased, the contribution rate of direct photolysis and $\mathrm{SO}_{4}^{--}$to TMP degradation did not change significantly, and the contribution rate of ${ }^{\circ} \mathrm{OH}$ dropped significantly. The possible reason was that $k_{\mathrm{FA}, \cdot \mathrm{OH}}\left(3.0 \times 10^{8} \mathrm{M}_{\mathrm{C}}^{-1} \mathrm{~s}^{-1}\right)$ was larger than $k_{\mathrm{FA}, \mathrm{SO}_{4}^{-}}\left(2.35 \times 10^{7} \mathrm{M}_{\mathrm{C}}^{-1} \mathrm{~s}^{-1}\right.$ ) (Weishaar et al. 2003; Xie et al. 2015).

\section{Effect of inorganic anions}

Inorganic anions present in environmental water (e.g., $\mathrm{SO}_{4}^{2-}, \mathrm{NO}_{3}^{-}, \mathrm{Cl}^{-}$, and $\mathrm{HCO}_{3}^{-}$) also have a greater effect on the degradation of TMP by UV/PS. In this study, the effect of inorganic ions on the degradation kinetics of $\mathrm{SO}_{4}^{--}$was studied by adding anion concentrations close to those in the environment in deionized water $\left(\mathrm{SO}_{4}^{2-}\right.$ and $\mathrm{NO}_{3}^{-}$concentration of $0.5 \mathrm{mM}, \mathrm{Cl}^{-}$and $\mathrm{HCO}_{3}^{-}$the concentration is $1 \mathrm{mM}$ ). The results (Fig. 6) show that $\mathrm{SO}_{4}^{2-}$ has little effect on the degradation of TMP, while $\mathrm{HCO}_{3}^{-}$will promote the degradation of TMP $(11.5 \%)$. The main reason why $\mathrm{HCO}_{3}^{-}$promotes the TMP degradation in the UV/PS system is that $\mathrm{HCO}_{3}^{-}$can react with $\mathrm{SO}_{4}^{--}$to produce $\mathrm{CO}_{3}^{--}(1.59 \mathrm{~V} \mathrm{NHE})$, which has certain oxidation ability. The oxidation potential of $\mathrm{CO}_{3}^{\circ-}$ was $1.59 \mathrm{~V}$ vs NHE (Giannakis et al. 2021). The secondary free radicals $\mathrm{CO}_{3}^{--}$can continue to react with TMP (Lian et al. 2017; Luo et al. 2016b; Zuo et al. 1999). $\mathrm{NO}_{3}^{-}$and $\mathrm{Cl}^{-}$will inhibit the degradation of TMP, and the inhibition rates are $32.1 \%$ and
$20.4 \%$, respectively. $\mathrm{NO}_{3}^{-}$can produce ${ }^{\circ} \mathrm{OH}, \mathrm{NO}_{3}^{-}$, and $\mathrm{NO}_{2}^{-}$ under a series of complex reactions under $\mathrm{UV}$ and sunlight (Dong and Rosario-Ortiz 2012; Ji et al. 2012; Keen et al. 2012; Vione et al. 2006; Xiao et al. 2014). The oxidation potentials of $\mathrm{NO}_{3}^{--}$and $\mathrm{NO}_{2}^{--}$were $2.3-2.5 \mathrm{~V}$ and $1.03 \mathrm{~V}$, respectively (Giannakis et al. 2021). However, ${ }^{\circ} \mathrm{OH}, \mathrm{NO}_{2}^{\circ-}$, and $\mathrm{NO}_{2}^{-}$have lower quantum yields, $\Phi_{\cdot \mathrm{OH} / \mathrm{NO}_{2}^{-}}=0.24$, $\Phi_{\mathrm{NO}_{2}^{-}}=0.015 \sim 0.028$ mol Einstein ${ }^{-1}$ (Keen et al. 2012). According to Keen's calculation, the $\left[\mathrm{HO}^{\circ}\right]_{\mathrm{Ss}}$ produced by UV excitation $0.5 \mathrm{mM} \mathrm{NO}_{3}^{-}$is only $0.74 \times 10^{-18} \mathrm{M}$ (Keen et al. 2012). At the same time, $\mathrm{NO}_{3}^{-}$can also quench ${ }^{\circ} \mathrm{OH} /$ $\mathrm{SO}_{4}^{--}$. In the $\mathrm{UV} / \mathrm{S}_{2} \mathrm{O}_{8}^{2-}$ system, $\mathrm{Cl}^{-}$and $\mathrm{SO}_{4}^{--}$can react to produce a series of new secondary free radicals, such as $\mathrm{Cl}^{\circ}$, $\mathrm{ClOH}^{-}$, and $\mathrm{Cl}_{2}^{--}$(Luo et al. 2016b). The oxidation potentials of $\mathrm{Cl}^{\circ}, \mathrm{ClOH}^{\circ-}$ and $\mathrm{Cl}_{2}^{\circ-}$ were $1.9 \mathrm{~V}, 2.47 \mathrm{~V}$, and $2.0 \mathrm{~V}$, respectively (Giannakis et al. 2021). On the one hand, $\mathrm{Cl}^{-}$can quench $\mathrm{SO}_{4}^{--}$(Lian et al. 2017; Yang et al. 2014; Yang et al. 2016). On the other hand, the generated secondary free radicals can continue to oxidatively degrade TMP. $\mathrm{Cl}^{\circ}$ and $\mathrm{Cl}_{2}^{-}$ have strong oxidation ability. The oxidation potentials of $\mathrm{Cl}^{\circ}$ and $\mathrm{Cl}_{2}^{-}$were $2.47 \mathrm{~V}$ and $2.0 \mathrm{~V}$, respectively (Beitz et al. 1998). $\mathrm{Cl}^{\circ}$ is also a selective oxidant, which can react with electron-rich components through electron transfer, hydrogen extraction, and addition (Beitz et al. 1998). Therefore, the contribution of secondary free radicals $\left(\mathrm{Cl}^{\circ}, \mathrm{ClOH}^{-}\right.$, and $\mathrm{Cl}_{2}^{--}$) and the inhibition of $\mathrm{Cl}^{-}$comprehensive determine the effect on TMP degradation.

The effect of $\mathrm{Cl}^{-}$on TMP degradation was studied using concentrations ranging from 0 to $5 \mathrm{mM}$. As shown in Fig. 7, for the effect of $\mathrm{Cl}^{-}, k_{\text {obs }}$ slightly decreased from $11.36 \times 10^{-3}$ $\mathrm{s}^{-1}$ in the absence of $\mathrm{Cl}^{-}$to $5.73 \times 10^{-3} \mathrm{~s}^{-1}$ in the presence of $5 \mathrm{mM} \mathrm{Cl}^{-}$. The negative effect of $\mathrm{Cl}^{-}$in the system might result from the fact that significant amounts of $\mathrm{SO}_{4}^{--}$react with $\mathrm{Cl}^{-}$forming chloride-derived radicals. For instance, the influence of $\mathrm{Cl}^{-}$depended on its fast rate constants with both ${ }^{\circ} \mathrm{OH}$ and $\mathrm{SO}_{4}^{--}$(Eqs. 22 and 23 in Table 2). Usually, the fast

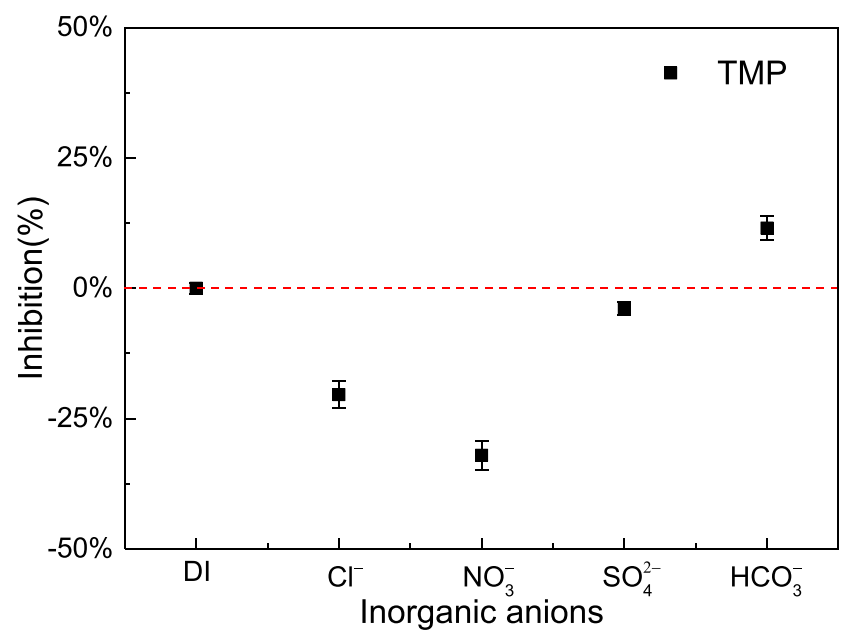

Fig. 6 Inhibition of inorganic anions on TMP degradation in DI water 


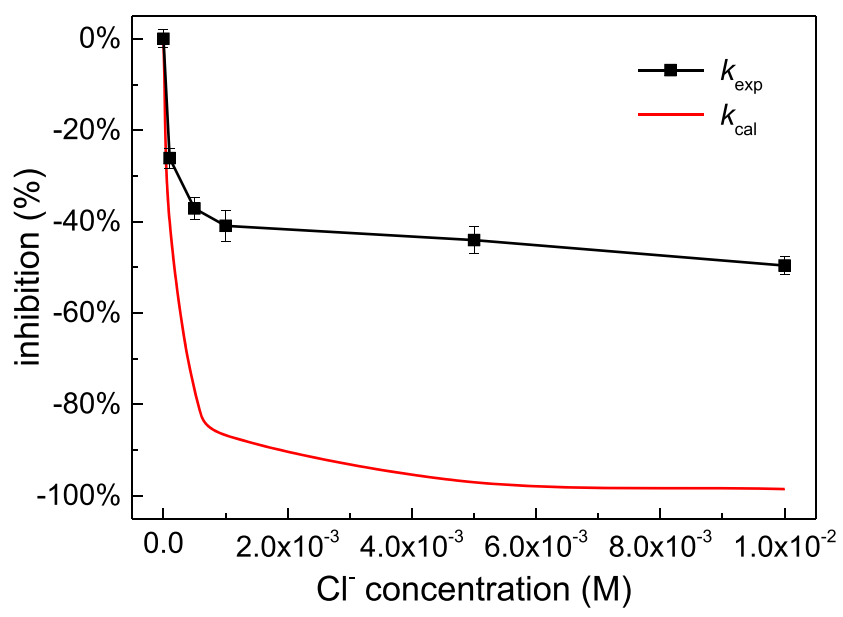

Fig. 7 Impacts of $\mathrm{Cl}^{-}$on the degradation of TMP ([TMP $]_{0}=10 \mu \mathrm{M}$, $[\mathrm{PS}]_{0}=200 \mu \mathrm{M}, \mathrm{pH}=7.55$, and $E_{0}=7.496 \times 10^{-6}$ Einstein $\mathrm{L}^{-1} \mathrm{~s}^{-1}$ )

reaction of $\mathrm{SO}_{4}^{--}$with $\mathrm{Cl}^{-}$yields secondary reactive chlorine radical species, such as $\mathrm{Cl}^{-}, \mathrm{ClOH}^{*}$, and $\mathrm{Cl}_{2}^{--}$through complex chain reactions (i.e., Eqs. 24 to 31 in Table 2).

Since most of those rate constants of reactive chlorine radicals with TMP are relatively unknown, it is difficult to accurately predict how $\mathrm{Cl}^{-}$affected TMP degradation in the UV/PS process by the steady-state kinetic model. Thus, in this study, only $\mathrm{Cl}^{-}$ was considered the scavenger of ${ }^{\circ} \mathrm{OH}$ and $\mathrm{SO}_{4}^{--}$for calculating the $k_{\text {cal }}$ values. As shown in Fig. $6, k_{\text {cal }}$ was significantly smaller than the experimental data (red line), which contradicts the observation that $\mathrm{Cl}^{-}$had a minor inhibitory effect on TMP degradation. Still, those secondary radicals might play a role in the degradation of TMP in UV/PS process, since $\mathrm{Cl}^{\circ}$ and $\mathrm{Cl}_{2}^{-}$were strong oxidants with oxidation potentials of $2.47 \mathrm{~V}$ and $2.0 \mathrm{~V}$, respectively (Beitz et al. 1998). $\mathrm{Cl}^{\bullet}$ is a selective oxidant that reacts with electron-rich moieties through one-electron oxidation, H-abstraction, and addition to unsaturated bonds (Grebel et al. 2010). Previous studies had shown conflicting results of $\mathrm{Cl}^{-}$in the $\mathrm{UV} / \mathrm{S}_{2} \mathrm{O}_{8}^{2-}$ process, depending on the target compound. Yuan et al. (2011) reported that a dual effect of chloride (i.e., inhibitory and accelerating effect) on azo dye (Acid Orange 7) degradation in an emerging cobalt/peroxymonosulfate $(\mathrm{Co} /$ PMS) advanced oxidation process. Ghauch et al. (2017) showed that the $k$ value of chloramphenicol increased first and then decreased with the concentration increase of chloride anion in UV/ PS system. The reaction between ${ }^{\circ} \mathrm{OH} / \mathrm{SO}_{4}^{-}$and $\mathrm{Cl}^{-}$produces secondary chlorine radical species, but the influence of $\mathrm{Cl}^{-}$was compound dependent, either promoting target compound removal (Criquet and Leitner 2009; Fang et al. 2012), or inhibiting the degradation (Liang et al. 2006; Shah et al. 2013).

\section{Effect of transition metal ions}

Transition metal ions $\left(\mathrm{M}^{\mathrm{n}+}\right)$ were very common in industrial wastewater, and some research results showed that the presence of $\mathrm{M}^{\mathrm{n}+}$ had a very important effect on the degradation of organic matter by UV-activated persulfate system. As shown in Fig. 8, as the concentration of transition metal ions $\left(\mathrm{Cu}^{2+}, \mathrm{Zn}^{2+}, \mathrm{Co}^{2+}\right)$ in the UV/PS system increased from 0 to $100 \mu \mathrm{M}, k_{\exp }$ increased from $1.96 \times 10^{-3}$ to $2.44 \times 10^{-3}$, $3.11 \times 10^{-3}, 2.62 \times 10^{-3} \mathrm{~s}^{-1}$, respectively. The results showed that the presence of transition metal ions can significantly promote the degradation of TMP. Take $\mathrm{Co}^{2+}$ for example, The main reason was that transition metal ions can activate PS to produce more $\mathrm{SO}_{4}^{--}$, such as Eq. (12) (Liu et al. 2012; Nfodzo and Choi 2011).

$\mathrm{M}^{\mathrm{n}+}+\mathrm{S}_{2} \mathrm{O}_{8}^{2-} \rightarrow \mathrm{M}^{(\mathrm{n}+1)+}+\mathrm{SO}_{4}^{--}+\mathrm{SO}_{4}^{2-}$

At the same time, the generated $\mathrm{M}^{(\mathrm{n}+1)+}$ is not stable, and $\mathrm{M}^{(\mathrm{n}+1)+}$ oxidative degradation of TMP may be another main reason for the significant increase in $k_{\exp }$ (Liang et al. 2013).

However, as the concentration of transition metal ions $\left(\mathrm{Cu}^{2+}, \mathrm{Zn}^{2+}, \mathrm{Co}^{2+}\right)$ in the system continued to increase from 100 to $400 \mu \mathrm{M}, k_{\text {exp }}$ did not continue to increase but gradually decreased. The main reason was that excess transition metal ions can be combined with $\mathrm{SO}_{4}^{--}$to continue the reaction and consume free radicals (Eq. 24) (Furman et al. 2010; Nfodzo and Choi 2011), and excessive transition metal ions can also form hydrated ions with water (such as $\left[\mathrm{Zn}\left(\mathrm{H}_{2} \mathrm{O}\right)_{6}\right]^{2+}$ ) as UV contenders affected TMP and $\mathrm{S}_{2} \mathrm{O}_{8}^{2-}$ absorption of UV.

$\mathrm{M}^{\mathrm{n}+}+\mathrm{SO}_{4}^{--} \rightarrow \mathrm{M}^{(\mathrm{n}+1)+}+\mathrm{SO}_{4}^{2-}$

Transition metal ions showed a good synergistic effect in the UV/PS system. Only a very small amount of transition metal ions can significantly accelerate the degradation of organic pollutants, which provided a meaningful exploration for

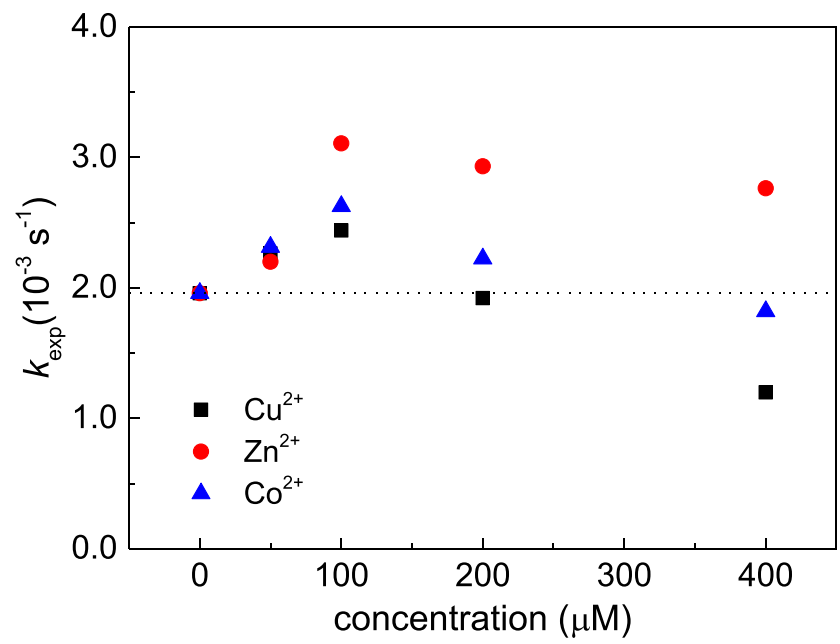

Fig. 8 Impacts of transition metal ions on the pseudo first-order constants of TMP $(k)\left([\mathrm{TMP}]_{0}=10 \mu \mathrm{M},[\mathrm{PS}]_{0}=100 \mu \mathrm{M}, \mathrm{pH}=7.55\right.$, and $E_{0}=$ $4.556 \times 10^{-6}$ Einstein $\left.\mathrm{L}^{-1} \mathrm{~s}^{-1}\right)$. 
the collaborative and comprehensive treatment of industrial wastewater.

\section{Conclusions}

The lower molar absorption coefficient and quantum yield limited the direct photolysis of TMP. After adding $\mathrm{H}_{2} \mathrm{O}_{2}$ or PS to the reaction system, the degradation effect of TMP was significantly enhanced, among which free radicals played a major role. $k_{\mathrm{HO}}{ }^{*}$ TMP and $k_{\mathrm{SO}_{4}^{-}, \mathrm{TMP}}$ showed good agreement with previously reported values, which was measured by competitive kinetics method and steady-state assumption model. Steady-state approximation and kinetic model were also developed in order to predict and simulate the destruction of TMP by a variety of water matrices in UV-activated persulfate system. $k_{\mathrm{obs}}$ of TMP degradation decreased in the presence of FA and $\mathrm{Cl}^{-}$, but $k_{\text {obs }}$ was increased with the concentration of PS. Transition metal ions had a good synergistic effect in UV/ PS degradation of TMP. However, excessive transition metal ions could reduce the TMP degradation due to the trapping effect of free radicals and the competition of formed hydrated ions against UV. The reported $k_{\mathrm{HO}}{ }^{-}$TMP and $k_{\mathrm{SO}_{4}^{-} \text {,TMP values }}$ and effect of matrix components are more beneficial to predict and explain TMP degradation mechanism and select more efficient radical-based advanced oxidation processes in engineered water.

Author contribution All authors contributed to the study conception and design. Material preparation, data collection, and analysis were performed by Yiting Luo, Rongkui Su, Haisong Yao, Aoshan Zhang, Siyuan Xiang, and Lei Huang. The first draft of the manuscript was written by Yiting Luo and Rongkui Su, and all authors commented on the previous versions of the manuscript. All authors read and approved the final manuscript.

Funding This work was supported by the National Nature Science Foundation of China (No. 52000183), China Postdoctoral Science Foundation (2020M683665XB), Key Laboratory of Jiangxi Province for Persistent Pollutants Control and Resources Recycle Open Fund (No. ES202080088), Key Project of Scientific Research Project of Hunan Provincial Department of Education (20A523), Central South University of Forestry and Technology Introduced Talent Research Startup Fund (2020YJ010), Postdoctoral Oriented Training Program of Yunnan Province, and Hunan Provincial Innovation Foundation For Postgraduate (CX20200731).

Data availability Not applicable.

\section{Declarations}

Ethical approval Not applicable.

Consent to participate Not applicable.
Consent to publish Not applicable.

Competing interest The authors declare no competing interests.

\section{References}

Adams C, Wang Y, Loftin K, Meyer M (2002) Removal of antibiotics from surface and distilled water in conventional water treatment processes. J Environ Eng 128(3):253-260

Avetta P, Pensato A, Minella M, Malandrino M, Maurino V, Minero C, Hanna K, Vione D (2015) Activation of persulfate by irradiated magnetite: implications for the degradation of phenol under heterogeneous photo-fenton-like conditions. Environ Sci Technol 49(2): $1043-1050$

Baeza C, Knappe DR (2011) Transformation kinetics of biochemically active compounds in low-pressure UV photolysis and $\mathrm{UV} / \mathrm{H}_{2} \mathrm{O}_{2}$ advanced oxidation processes. Water Res 45(15):4531-4543

Beitz T, Bechmann W, Mitzner R (1998) Investigations of reactions of selected azaarenes with radicals in water. 2. chlorine and bromine radicals. J Phys Chem A 102(34):6766-6771

Beltran FJ, Ovejero G, Garcia-Araya JF, Rivas J (1995) Oxidation of polynuclear aromatic hydrocarbons in water. 2 . UV radiation and ozonation in the presence of UV radiation. Ind Eng Chem Res 34(5): $1607-1615$

Bougdour N, Tiskatine R, Bakas I, Assabbane A (2020) Textile wastewater treatment by peroxydisulfate/Fe(II)/UV: operating cost evaluation and phytotoxicity studies. Chemistry Africa 3(1):153-160

Bu Q, Wang B, Huang J, Deng S, Yu G (2013) Pharmaceuticals and personal care products in the aquatic environment in China: a review. J Hazard Mater 262(Supplement C):189-211

Buxton GV, Greenstock CL, Helman WP, Ross AB (1988) Critical review of rate constants for reactions of hydrated electrons, hydrogen atoms and hydroxyl radicals $\left(\cdot \mathrm{OH} / \mathrm{O}^{-}\right)$in aqueous solution. J Phys Chem Ref Data 17(2):513-886

Criquet J, Leitner NKV (2009) Degradation of acetic acid with sulfate radical generated by persulfate ions photolysis. Chemosphere 77(2): 194-200

Das TN (2001) Reactivity and role of $\mathrm{SO}_{5}{ }^{--}$radical in aqueous medium chain oxidation of sulfite to sulfate and atmospheric sulfuric acid generation. J Phys Chem A 105(40):9142-9155

Dong MM, Rosario-Ortiz FL (2012) Photochemical formation of hydroxyl radical from effluent organic matter. Environ Sci Technol 46(7): 3788-3794

Fang J-Y, Shang C (2012) Bromate formation from bromide oxidation by the UV/persulfate process. Environ Sci Technol 46(16):8976-8983

Fang GD, Dionysiou DD, Wang Y, Al-Abed SR, Zhou DM (2012) Sulfate radical-based degradation of polychlorinated biphenyls: effects of chloride ion and reaction kinetics. J Hazard Mater 227-228: 394-401

Fu J, Ji M, Wang Z, Jin L, An D (2006) A new submerged membrane photocatalysis reactor (SMPR) for fulvic acid removal using a nanostructured photocatalyst. J Hazard Mater 131(1):238-242

Furman OS, Teel AL, Watts RJ (2010) Mechanism of base activation of persulfate. Environ Sci Technol 44(16):6423-6428

Ghauch A, Baalbaki A, Amasha M, El Asmar R, Tantawi O (2017) Contribution of persulfate in UV-254nm activated systems for complete degradation of chloramphenicol antibiotic in water. Chem Eng J 317:1012-1025

Giannakis S, Lin K-YA, Ghanbari F (2021) A review of the recent advances on the treatment of industrial wastewaters by sulfate radicalbased advanced oxidation processes (SR-AOPs). Chem Eng J 406: 127083 
Grebel JE, Pignatello JJ, Mitch WA (2010) Effect of halide ions and carbonates on organic contaminant degradation by hydroxyl radical-based advanced oxidation processes in saline waters. Environ Sci Technol 44(17):6822-6828

Hou S, Ling L, Dionysiou DD, Wang Y, Huang J, Guo K, Li X, Fang J (2018) Chlorate formation mechanism in the presence of sulfate radical, chloride, bromide and natural organic matter. Environ Sci Technol 52(11):6317-6325

Huang Y, Kong M, Coffin S, Cochran K, Westerman D, Schlenk D, Richardson S, Lei L, Dionysiou D (2020) Degradation of contaminants of emerging concern by $\mathrm{UV} / \mathrm{H}_{2} \mathrm{O}_{2}$ for water reuse: kinetics, mechanisms, and cytotoxicity analysis. Water Res 174:115587

Jayson G, Parsons B, Swallow AJ (1973) Some simple, highly reactive, inorganic chlorine derivatives in aqueous solution. Their formation using pulses of radiation and their role in the mechanism of the fricke dosimeter. J Chem Soc Faraday T 69:1597-1607

Ji Y, Zeng C, Ferronato C, Chovelon J-M, Yang X (2012) Nitrateinduced photodegradation of atenolol in aqueous solution: kinetics, toxicity and degradation pathways. Chemosphere 88(5):644-649

Ji Y, Xie W, Fan Y, Shi Y, Kong D, Lu J (2016) Degradation of trimethoprim by thermo-activated persulfate oxidation: reaction kinetics and transformation mechanisms. Chem Eng J 286:16-24

Ji Y, Yang Y, Zhou L, Wang L, Lu J, Ferronato C, Chovelon J-M (2018) Photodegradation of sulfasalazine and its human metabolites in water by UV and UV/peroxydisulfate processes. Water Res 133:299309

Keen OS, Love NG, Linden KG (2012) The role of effluent nitrate in trace organic chemical oxidation during UV disinfection. Water Res 46(16):5224-5234

Kläning UK, Wolff T (1985) Laser flash photolysis of HCIO, CIO ${ }^{-}$, $\mathrm{HBrO}$, and $\mathrm{BrO}^{-}$in aqueous solution. Reactions of $\mathrm{Cl}^{-}$and $\mathrm{Br}^{-}$ atoms. Ber Bunsenges Phys Chem 89(3):243-245

Klaning UK, Sehested K, Appelman EH (1991) Laser flash photolysis and pulse radiolysis of aqueous solutions of the fluoroxysulfate ion, $\mathrm{SO}_{4} \mathrm{~F}$. Inorg Chem 30(18):3582-3584

Kwon M, Kim S, Yoon Y, Jung Y, Hwang T, Lee J, Kang J (2015) Comparative evaluation of ibuprofen removal by $\mathrm{UV} / \mathrm{H}_{2} \mathrm{O}_{2}$ and $\mathrm{UV} / \mathrm{S}_{2} \mathrm{O}_{8}{ }^{2-}$ processes for wastewater treatment. Chem Eng J 269: 379-390

Lian L, Yao B, Hou S, Fang J, Yan S, Song W (2017) Kinetic study of hydroxyl and sulfate radical-mediated oxidation of pharmaceuticals in wastewater effluents. Environ Sci Technol 51(5):2954-2962

Liang Cj, Wang ZS, Mohanty N (2006) Influences of carbonate and chloride ions on persulfate oxidation of trichloroethylene at $20{ }^{\circ} \mathrm{C}$. Sci Total Environ 370(2-3):271-277

Liang Hy, Zhang Yq, Huang Sb, Hussain I (2013) Oxidative degradation of p-chloroaniline by copper oxidate activated persulfate. Chem Eng J 218:384-391

Lin H, Ai J, Li R, Deng L, Tan W, Ye Z, Wu X, Zhang H (2020) Treatment of organosilicon wastewater by UV-based advanced oxidation processes: performance comparison and fluorescence parallel factor analysis. Chem Eng J 380:122536

Liu CS, Shih K, Sun CX, Wang F (2012) Oxidative degradation of propachlor by ferrous and copper ion activated persulfate. Sci Total Environ 416:507-512

Luo C, Jiang J, Ma J, Pang S, Liu Y, Song Y, Guan C, Li J, Jin Y, Wu D (2016a) Oxidation of the odorous compound 2,4,6-trichloroanisole by UV activated persulfate: kinetics, products, and pathways. Water Res 96:12-21

Luo CW, Jiang J, Ma J, Pang SY, Liu YZ, Song Y, Guan CT, Li J, Jin YX, Wu DJ (2016b) Oxidation of the odorous compound 2,4,6trichloroanisole by UV activated persulfate: kinetics, products, and pathways. Water Res 96:12-21

Lutze HV, Bircher S, Rapp I, Kerlin N, Bakkour R, Geisler M, von Sonntag C, Schmidt TC (2015) Degradation of chlorotriazine pesticides by sulfate radicals and the influence of organic matter. Environ Sci Technol 49(3):1673-1680

McElroy WJ (1990) A laser photolysis study of the reaction of $\mathrm{SO}_{4}{ }^{-}$with $\mathrm{Cl}^{-}$and the subsequent decay of $\mathrm{Cl}_{2}^{-}$in aqueous solution. $\mathrm{J}$ Phys Chem 94(6):2434-2441

Naim S, Ghauch A (2016) Ranitidine abatement in chemically activated persulfate systems: assessment of industrial iron waste for sustainable applications. Chem Eng J 288:276-288

Neta P, Madhavan V, Zemel H, Fessenden RW (1977) Rate constants and mechanism of reaction of sulfate radical anion with aromatic compounds. J Am Chem Soc 99(1):163-164

Nfodzo P, Choi H (2011) Triclosan decomposition by sulfate radicals: effects of oxidant and metal doses. Chem Eng J 174(2):629-634

Nikravesh B, Shomalnasab A, Nayyer A, Aghababaei N, Zarebi R, Ghanbari F (2020) UV/Chlorine process for dye degradation in aqueous solution: mechanism, affecting factors and toxicity evaluation for textile wastewater. Journal of Environmental Chemical Engineering 8(5): 104244

Parker CA, 1953 A new sensitive chemical actinometer. I. Some trials with potassium ferrioxalate. Proceedings of the Royal Society A 220 (1140), 104-116

Pereira VJ, Weinberg HS, Linden KG, Singer PC (2007) UV degradation kinetics and modeling of pharmaceutical compounds in laboratory grade and surface water via direct and indirect photolysis at $254 \mathrm{~nm}$. Environ Sci Technol 41(5):1682-1688

Ran G, Li Q (2020) Degradation of refractory organic compounds from dinitrodiazophenol containing industrial wastewater through UV/ $\mathrm{H} 2 \mathrm{O} 2$ and UV/PS processes. Environ Sci Pollut R 27(6):6042-6051

Shah NS, He X, Khan HM, Khan JA, O'Shea KE, Boccelli DL, Dionysiou DD (2013) Efficient removal of endosulfan from aqueous solution by UV-C/peroxides: a comparative study. J Hazard Mater 263(Part 2):584-592

Stumm W, Morgan J (1996) Aquatic chemistry: chemical equilibria and rates in natural waters. Wiley, New York

Su R, Chai L, Tang C, Li B, Yang Z (2018) Comparison of the degradation of molecular and ionic ibuprofen in a $\mathrm{UV} / \mathrm{H}_{2} \mathrm{O}_{2}$ system. Water Sci Technol 77(9):2174-2183

Sui Q, Wang B, Zhao W, Huang J, Yu G, Deng S, Qiu Z, Lu S (2012) Identification of priority pharmaceuticals in the water environment of China. Chemosphere 89(3):280-286

Tang T, Lu G, Wang R, Qiu Z, Huang K, Lian W, Tao X, Dang Z, Yin H (2019) Rate constants for the reaction of hydroxyl and sulfate radicals with organophosphorus esters (OPEs) determined by competition method. Ecotox Environ Safe 170:300-305

Vione D, Falletti G, Maurino V, Minero C, Pelizzetti E, Malandrino M, Ajassa R, Olariu R-I, Arsene C (2006) Sources and sinks of hydroxyl radicals upon irradiation of natural water samples. Environ Sci Technol 40(12):3775-3781

Wan Y, Xie P, Wang Z, Ding J, Wang J, Wang S, Wiesner MR (2019) Comparative study on the pretreatment of algae-laden water by UV/ persulfate, $\mathrm{UV} /$ chlorine, and $\mathrm{UV} / \mathrm{H}_{2} \mathrm{O}_{2}$ : variation of characteristics and alleviation of ultrafiltration membrane fouling. Water Res 158: 213-226

Wei Z, Villamena FA, Weavers LK (2017) Kinetics and mechanism of ultrasonic activation of persulfate: an in situ EPR spin trapping study. Environ Sci Technol 51(6):3410-3417

Weishaar JL, Aiken GR, Bergamaschi BA, Fram MS, Fujii R, Mopper K (2003) Evaluation of specific ultraviolet absorbance as an indicator of the chemical composition and reactivity of dissolved organic carbon. Environ Sci Technol 37(20):4702-4708

Xiao Yj, Fan R1, Zhang Lf, Yue Jq, Webster RD, Lim TT (2014) Photodegradation of iodinated trihalomethanes in aqueous solution by UV 254 irradiation. Water Res 49:275-285

Xie PC, Ma J, Liu W, Zou J, Yue SYC, Li X, Wiesner MR, Fang JY (2015) Removal of 2-MIB and geosmin using UV/persulfate: contributions of hydroxyl and sulfate radicals. Water Res 69:223-233 
Yang Y, Pignatello JJ, Ma J, Mitch WA (2014) Comparison of halide impacts on the efficiency of contaminant degradation by sulfate and hydroxyl radical-based advanced oxidation processes (AOPs). Environ Sci Technol 48(4):2344-2351

Yang Y, Pignatello JJ, Ma J, Mitch WA (2016) Effect of matrix components on $\mathrm{UV} / \mathrm{H}_{2} \mathrm{O}_{2}$ and $\mathrm{UV} / \mathrm{S}_{2} \mathrm{O}_{8}{ }^{2-}$ advanced oxidation processes for trace organic degradation in reverse osmosis brines from municipal wastewater reuse facilities. Water Res 89:192-200

Yang ZH, Su RK, Luo S, Spinney R, Cai MQ, Xiao RY, Wei ZS (2017) Comparison of the reactivity of ibuprofen with sulfate and hydroxyl radicals: an experimental and theoretical study. Sci Total Environ: 590-591-751-760

$\mathrm{Yu}$ XY, Bao ZC, Barker JR (2004) Free radical reactions involving $\mathrm{Cl}^{\circ}$, $\mathrm{Cl}_{2}{ }^{--}$, and $\mathrm{SO}_{4}{ }^{-{ }^{-}}$in the $248 \mathrm{~nm}$ photolysis of aqueous solutions containing $\mathrm{S}_{2} \mathrm{O}_{8}{ }^{2-}$ and Cl. J Phys Chem A 108(2):295-308

Yuan F, Hu C, Hu Xx, Qu Jh, Yang M (2009) Degradation of selected pharmaceuticals in aqueous solution with $\mathrm{UV}$ and $\mathrm{UV} / \mathrm{H}_{2} \mathrm{O}_{2}$. Water Res 43(6):1766-1774

Yuan R, Ramjaun SN, Wang Z, Liu J (2011) Effects of chloride ion on degradation of Acid Orange 7 by sulfate radical-based advanced oxidation process: implications for formation of chlorinated aromatic compounds. J Hazard Mater 196:173-179

Zhang R, Sun P, Boyer TH, Zhao L, Huang C-H (2015) Degradation of pharmaceuticals and metabolite in synthetic human urine by UV, $\mathrm{UV} / \mathrm{H}_{2} \mathrm{O}_{2}$, and UV/PDS. Environ Sci Technol 49(5):3056-3066

Zhang B, Wang X, Fang Z, Wang S, Shan C, Wei S, Pan B (2021) Unravelling molecular transformation of dissolved effluent organic matter in $\mathrm{UV} / \mathrm{H}_{2} \mathrm{O}_{2}$, UV/persulfate, and UV/chlorine processes based on FT-ICR-MS analysis. Water Res 199:117158-117158

Zhao R, Feng J, Liu J, Fu W, Li X, Li B (2019) Deciphering of microbial community and antibiotic resistance genes in activated sludge reactors under high selective pressure of different antibiotics. Water Res 151:388-402

Zuo Z, Cai Z, Katsumura Y, Chitose N, Muroya Y (1999) Reinvestigation of the acid-base equilibrium of the (bi) carbonate radical and $\mathrm{pH}$ dependence of its reactivity with inorganic reactants. Radiat Phys Chem 55(1):15-23

Publisher's note Springer Nature remains neutral with regard to jurisdictional claims in published maps and institutional affiliations. 